\title{
Stages of Learning Motivation: Development and Validation of a Measure ${ }^{1}$
}

\author{
Michael S. COLE ${ }^{2}$ \\ Institute for Leadership and Human Resource Management \\ University of St. Gallen \\ StAnley G. HARris AND Hubert S. FeILD \\ Department of Management \\ Auburn University
}

\begin{abstract}
Prochaska and colleagues' (e.g., Prochaska, DiClemente, \& Norcross, 1992) stages-ofchange theory was employed in the current study to reconceptualize the assessment of motivation to learn. We used the stages-of-change framework to develop and test a multidimensional measure of learning motivation using 3 independent samples. The pattern of relationships among the learning stages and learning criteria provided strong support for the appropriateness of using a stage-based perspective to frame learning motivation. In addition, hierarchical regression analysis showed that the Stages of Learning Motivation Inventory (SOLMI) explained variance in the criteria (e.g., exam average, class satisfaction) beyond controls and a commonly used measure of learning motivation. Implications for practice and future research are discussed.
\end{abstract}

The past decade has seen a burgeoning interest in how personal characteristics are related to training effectiveness, as well as why, when, and for whom training is most effective (Tannenbaum \& Yukl, 1992). A better understanding of the attributes - including ability, motivation, and work environment (e.g., Goldstein, 1993; Noe \& Schmitt, 1986) — that influence individuals' trainability could provide important insight into the ultimate effectiveness of training and learning endeavors (Campbell, 1989; Noe, 1986). Although most of the early trainability literature focused on trainees' ability, research on motivation to learn has been increasing (Colquitt, LePine, \& Noe, 2000). Motivation to learn influences decision-making processes regarding the direction, focus, and level of effort applied to a learning activity (Noe, Wilk, Mullen, \& Wanek, 1997).

1The authors thank Jason A. Colquitt and two anonymous reviewers for their helpful comments on earlier drafts of this manuscript.

${ }^{2}$ Correspondence concerning this article should be addressed to Michael S. Cole, University of St. Gallen, Institute for Leadership and Human Resource Management, Dufourstrasse 40a, CH-9000 St. Gallen, Switzerland. E-mail: Michael.Cole@unisg.ch

\section{1}

Journal of Applied Social Psychology, 2004, 34, 7, pp. 1421-1456.

Copyright $(\mathcal{C} 2004$ by V. H. Winston \& Son, Inc. All rights reserved. 
In general, the training literature has acknowledged that learning motivation can be affected by individual and situational characteristics (e.g., Baldwin, Magjuka, \& Loher, 1991; Goldstein, 1993; Mathieu \& Martineau, 1997; Mathieu, Tannenbaum, \& Salas, 1992). For example, researchers have examined the relevance of individuals' personality and cognitive ability, as well as an organization's climate in predicting learning motivation and transfer (e.g., Colquitt et al., 2000). In turn, learning motivation is reported to exhibit a positive relationship with learning outcomes (Colquitt \& Simmering, 1998; Mathieu et al., 1992; Quinones, 1995).

Despite the demonstrated positive relationships between motivation to learn and important criteria, those relationships are often weak. For example, three recent studies reported that pre-training motivation explained only $2 \%$ of the incremental variance in participants' post-training learning (Baldwin et al., 1991; Colquitt \& Simmering, 1998; Mathieu et al., 1992). What might account for the relatively weak predictive ability of learning motivation with key learning criteria? We believe that using current conceptualizations and measures of motivation to learn to assess motivation in training environments has limited research in at least two ways. First, they have emphasized a static rather than a dynamic view of motivation. Second, they may underestimate the role of motivation because they are largely unidimensional and do not fully capture motives and behaviors that are associated with qualitatively different motivational states.

Current conceptualizations and measurement typically emphasize a static rather than a dynamic view of learning (typically pre-training) motivation. Most recent research depicts pre-training motivation as an exogenous variable, assessed at one point in time, and linked to learning processes or other learning criteria (e.g., performance). The dominant theoretical perspectives on learning motivation (and its measurement) build off of expectancy theory and focus on self-efficacy or valence-instrumentality-expectancy composites (Mathieu \& Martineau, 1997). While these theories accommodate the idea that expectancies, motives, and valences can change over time, they do not emphasize such dynamism. In our view, such an approach biases research against considering the possibility that learning motivation may change over time and that individuals might progress (or regress) through various motivational states.

A second possible bias in current conceptualizations and measures of motivation to learn is related to the first. Specifically, the static view of learning motivation engenders a unidimensional approach to motivation built off of expectancy theory. The prevailing assumption presumes that learning motivation is not comprised of different dimensions, only varying degrees. When measuring motivation to learn, some researchers adopt the scale developed by Noe and Schmitt (1986), while others have added items to Noe and Schmitt's scale, and still others have developed entirely new measures (e.g., Baldwin et al., 1991; 
Mathieu et al., 1992; Noe \& Wilk, 1993; Quinones, 1995). In each case, however, the measure focuses on unidimensional degrees of desire and learning behavior. For example, all of these measures share an underlying assumption that the individual is already aware of a learning opportunity.

But if a person is truly in a state of being unaware of a learning opportunity, is it reasonable to assume that they can accurately express the expectancy, instrumentality, and valence of such learning? What about a person who is forced or coerced into a learning opportunity, who feels it is unnecessary, and who is motivated only to learn enough to satisfy some requirement? Such a ticket-punch approach to learning may in fact interfere with long-term knowledge acquisition and retention. Unfortunately, current approaches to learning motivation make capturing such reluctant, short-term motivation difficult. Furthermore, current measures do not allow a distinction to be drawn between mental motivation and readiness, and readiness to become actively involved. In sum, we were unable to locate any measures or research that explored the proposition that individuals' motivation to learn is multidimensional and dynamic.

In response to these concerns, we offer a multidimensional, dynamic approach to understanding motivation to learn drawn from the transtheoretical model (also known as the stage model), a leading approach to health behavioral change, originally formulated by Prochaska (1979). We feel this stage-based approach to learning motivation has the benefit of capturing the dynamic movement between multiple and qualitatively unique motivational states that are presently obscured by current approaches to learning motivation. Applying insights from the transtheoretical model to learning motivation adds to the traditional unidimensional theoretical underpinnings of the concept by acknowledging that one is not always conscious of a learning opportunity or need, and then emphasizing the progression and thought processes that take an individual from awareness to contemplating action to activated learning behaviors. Guided by the transtheoretical model, we then describe the development and initial validation of a multidimensional, stage-based measure of individuals' motivation to learn within a university classroom setting.

\section{A Stage-Based Perspective on Motivation to Learn}

Developed as an integrative model of intentional behavioral change, Prochaska (1979) emphasized the roles of need awareness, readiness, and level of motivation to change when he conceptualized the transtheoretical model (TTM) of behavioral change. Incorporating motivational, cognitive, social learning, and relapse prevention theories, the TTM has received an extensive amount of supporting empirical evidence with regard to positive behavioral change in psychotherapy and therapeutic contexts (e.g., smoking cessation, weight control, reducing adolescent delinquent behaviors). For instance, DiClemente and 
Prochaska (1982), in one of the early TTM studies, found strong evidence for individuals' progression through distinct stages of change characterized by different levels of awareness, motivations, concerns, and intervention requirements. This study was the foundation for a series of studies (e.g., Prochaska \& DiClemente, 1982, 1983b) providing the framework for categorizing stages-ofchange motivation and, ultimately, interventions appropriate to support progress at each stage. ${ }^{3}$

\section{Stages of Change}

The principal construct of the TTM, stages of change, describes five stages in the change process, each characterized by different motivations (Levesque et al., 2001). As described by Prochaska et al. (1992), in the first stage, precontemplation, individuals are either unaware of the need for change or feel coerced into changing and have no intention of changing. In the second stage, contemplation, individuals are aware of a need to change and are actively deciding if they are able or motivated to make the change. In the third stage, preparation, individuals have decided to change and are making plans to do so in the near future or are in the early stages of initiating those changes. During the fourth stage, action, individuals are taking the actual steps necessary for change and may seek help to further accomplish change. In the fifth and final stage, maintenance, individuals focus on the prevention of relapsing to pre-change behaviors. Consistent with the training motivation literature, self-efficacy is an important component in the stage model, with self-efficacy levels increasing as individuals advance through the stages of change (Prochaska, DiClemente, Velicer, Ginpil, \& Norcross, 1985).

A major benefit of the stages-of-change approach to understanding motivation to undertake change, including learning, is that it identifies processes that are used in each stage to facilitate stage advancement (Prochaska et al., 1992). Research has shown that matching outside interventions to the stage of the individual can more than double the likelihood that individuals will take action (Prochaska, DiClemente, Velicer, \& Rossi, 1993). Based on an assessment of respondents' change stage, Prochaska et al. (1994) were able to predict the decisional processes and techniques that facilitated individuals to make progress across 12 different personal changes. In general, consciousness raising, selfevaluation, education, and reflection are the interventions most appropriate to motivate change action for those in the precontemplation and contemplation stages. More behavioral, skill-based, reinforcement-based, action-oriented interventions seem best suited for continuing the change actions of those already in the action and maintenance stages.

\footnotetext{
${ }^{3}$ For a detailed review of the TTM, see Prochaska, DiClemente, and Norcross (1992), or visit Prochaska's website at http://www.uri.edu/research/cprc/Faculty/JProchaska.htm
} 
Prochaska's findings have far-reaching implications for the one-size-fits-all approach frequently employed by trainers during education and training programs. For example, an appropriate intervention for someone in the precontemplation learning motivation stage should emphasize the need for and advantages of learning the material. Such intervention for someone in the action stage would be wasteful. Contemplators need encouragement and matched interventions designed to increase valence and feelings of efficacy regarding the potential learning activity. Those in the preparation stage require interventions focused on encouragement and support with early learning efforts. Individuals already taking action need interventions that facilitate meeting their learning needs (e.g., access to information and competent instruction).

Although the stages of change have received attention in therapeutic contexts, researchers have only recently begun to apply Prochaska's theory in organizational settings (e.g., Levesque, Prochaska, \& Prochaska, 1999; Levesque et al., 2001; Prochaska, 2000). Our search yielded only one application in the domain of learning: Harris and Cole (1999) applied Prochaska's model and measurement approach to assess managers' readiness and motivation to participate in a leadership development program. Their results were consistent with the motivational framework underlying Prochaska's theory. For example, they found relationships between participants' stages-of-change sentiments and their perceived desire to learn about certain topics, as well as their evaluation of both course content and instructors. While Harris and Cole's work demonstrated the advantages of using the model in an organizational learning environment, they also noted the need for improving the measurement of the model's stages in such a context.

\section{Research Goals and Hypotheses}

The goals of the research reported here are to design, refine, and examine the validity of a stages of learning motivation inventory (SOLMI) modeled after the stages-of-change measures employed by Prochaska and others. Therefore, we wanted to create an instrument that would assess the degree to which respondents' attitudes, motivations, and behaviors were consistent with each stage of change. While the resulting SOLMI provides a template for use in different educational settings, in the present study it was designed to assess student motivation to learn in a university course.

Classroom-based learning is an important form of personal change and, based on Prochaska's model, motivation for such learning should be manifested in different stages. Learning class material often requires students to change not only their attitudes regarding the class, but also their behavior. Therefore, in an educational context, each stage of change can be considered a stage of learning motivation. For example, individuals in the precontemplation learning motivation stage either do not realize they have a need to learn something or may feel 
coerced into learning something that they do not value (e.g., students enrolled in a required class that they do not want to take and see no need in taking).

Given our research context (short, quarter-long university course), we decided that it was not appropriate to expect or try to measure the maintenance stage. Therefore, the SOLMI was designed to assess only the first four stages of change (precontemplation, contemplation, preparation, and action) by providing a scale score for each. Our validity examinations of the resulting inventory are built around four hypotheses.

First, it is important to show that the SOLMI operates in a manner consistent with the stages-of-change theory. Because each of the SOLMI scales denotes a distinct stage of learning motivation, we expect individuals' scale scores will exhibit a peaked profile. That is, the stage theory of learning motivation implies that persons are primarily in one stage at a time. Based on this discussion, we formed the following hypothesis:

\section{Hypothesis 1. Students will score higher on one stage of change} than on others.

Since the action stage involves actual behavioral engagement in the learning process, the earlier students achieve this stage, the more time and energy they have to engage in positive learning behaviors (e.g., class attendance) and active learning (as may be reflected in performance on exams). In addition, it is more likely that they will appreciate the learning opportunity provided to them. Students in earlier stages will spend more time and energy resisting learning or becoming aware of the need to learn, and their classroom behavior, performance, and attitudes should suffer by comparison. We, therefore, formed the following hypothesis:

Hypothesis 2. Students who occupy the action stage earlier during the academic term will have higher attendance, exam scores, and class satisfaction than those occupying other stages.

Next, we examine how students' learning motivation stage interacts at two points in time to explain learning behaviors, performance, and class attitudes. Because it is a stage model, we would expect some students to progress, others to regress, and others to remain unchanged with regard to their stage of motivation. Movement between stages makes interpretation of the relationships between the stages and criteria difficult. To account for this potential movement, we use students' learning motivation stages at the beginning and end of the academic term to evaluate more fully the relationships between the criterion variables and the stages of learning motivation. For example, being in the action stage at both administrations should result in the highest classroom performance, as reflected in exam scores. Also positive progression into the action stage should 
be associated with better performance than remaining static in a lower stage or regressing to a lower stage. Therefore, we hypothesize the following:

Hypothesis 3. Students' occupied stages at the beginning and end of the academic term will interact and explain students' classroom performance. Students static in the action phase will perform best, those progressing to the action stage will perform next best, and students regressing in stage or remaining static in a stage below action will perform relatively worse.

Finally, if the multidimensional approach to understanding and assessing individuals' learning motivation offered by the stages-of-change model extends current unidimensional assessments of learning motivation, then its assessment by the SOLMI should account for variation in relevant learning criteria beyond that explained by traditional measures. Conceptually, traditional treatments of learning motivation focus on the desire to learn and the effort expended to learn while taking the awareness of the learning opportunity for granted. Compared with the stage-based approach to learning motivation, effort and desire overlap most with the sentiments reflected in the action and preparation stages, while the motivational states of precontemplation and contemplation are relatively neglected. Therefore, within the SOLMI, we expect the precontemplation and contemplation attitudes to explain the most unique variance beyond that explained by traditional learning motivation measures:

Hypothesis 4. The SOLMI will explain incremental variance in learning criteria (students' exam average, class attendance, class satisfaction, and help-seeking behaviors) beyond that accounted for by traditional measures employed to assess learning motivation sentiments. In addition, the motivational states of precontemplation and contemplation of the SOLMI will account for most of this unique variance.

\section{SOLMI Development}

The instruments used by Prochaska and his colleagues (e.g., McConnaughy, DiClemente, Prochaska, \& Velicer, 1989) and Harris and Cole (1999) were reviewed and their items modified to develop an initial pool of items to assess the four stages of learning motivation. No previous items existed to capture the preparation stage. Prochaska et al. (1992) argued that high scores on contemplation and action depict the preparation stage and, thus, did not develop items to tap preparation explicitly. To avoid the problem of mixing item specificity (e.g., motivation for general learning versus motivation for learning content in a 
particular class), all items were written to refer to the learning environment represented in the specific introductory management class being surveyed (three different classes ultimately were surveyed).

A small focus group consisting of two management professors and three doctoral candidates was assembled to review and comment on the items. Following a discussion of Prochaska's (Prochaska et al., 1992) TTM theory and its applicability in an educational setting, the group judged each item's applicability to the four learning motivation constructs. As a result of these efforts, 20 items were identified for inclusion in the initial Stages of Learning Motivation Inventory. Precontemplation (e.g., "It doesn't make sense for me to attend all of this course's lectures") and contemplation (e.g., "I am hoping this course will help me to better understand management principles") scales consisted of 5 items each. Six items (e.g., "I have started working to improve my learning in this course, but would like help") were developed to measure the preparation stage. Finally, 4 items (e.g., "I am really working hard to improve my knowledge of this course's information") were designed to assess the action stage. All items were assessed on a 6-point Likert scale ranging from 1 (strongly disagree) to 6 (strongly agree).

When developing and validating new items, DeVellis (1991) suggested using independent samples to increase the generalizability of a measure's dimensionality. Therefore, to adequately develop and refine the SOLMI instrument, the instrument was administered in a large Principles of Management class in the business school of a southeastern university (Sample 1), then refined and administered several months later in a large Management Information Systems class in the same university (Sample 2). A mixture of exploratory and confirmatory factor analyses was used to guide refinement efforts.

\section{Initial SOLMI Administration}

Participants and procedure. Sample 1 participants were 285 undergraduate students enrolled in a large Principles of Management course. The participants were primarily male $(59 \%)$ and White $(91 \%)$. Their average age was 22 years $(S D=2.7)$, with $98 \%$ classified as either a junior or senior. The class met four times per week ( 50 min each session) over the course of an academic quarter. Three sessions each week consisted of a lecture in a large auditorium. For the fourth session, the class was broken into smaller discussion/lab sections, and a lab instructor directed the activities. Lab instructors administered the SOLMI instrument during Week 3 of the course.

Analyses and results. Exploratory factor analysis of students' responses to the SOLMI was used to examine the inventory's dimensionality. Because the stagesof-change theory suggests that adjacent stages may be more correlated than non-adjacent stages (McConnaughy et al., 1989), oblique (direct oblimin) rotation was employed. Thompson and Daniel (1996) recommended the use of 
parallel analysis when making exploratory factor extraction decisions, and Zwick and Velicer (1986) reported research indicating that this technique is the most consistent and accurate method for determining an underlying factor structure. Conceptually, parallel analysis is a statistical procedure that compares observed eigenvalues with eigenvalues derived from random data (Coovert \& McNelis, 1988). Data matrices (i.e., real and random) are factor analyzed and factors are extracted from the real data for any real eigenvalues that are larger than the associated eigenvalues from the random data.

Based on these suggestions, a parallel analysis was conducted to help in the determination of the most appropriate underlying factor structure. For the current analysis, a $20 \times 285$ random data matrix was computed. The real and random data were factor analyzed, and their associated eigenvalues were compared. As expected, the four-factor model was the most valid and accounted for $64 \%$ of the common variance. By and large, three of the four factors corresponded with our preconceived four stages of learning motivation. Five of the six observed factor correlations between the four stages were significant $(p<.01)$. Only the correlation between the preparation and action scales was nonsignificant. Although our results suggested that the SOLMI basically captured the underlying four stages of learning motivation, item cross-loadings suggested that more instrument refinement was needed.

Based on Nunnally's (1978) suggestions, SOLMI items that exhibited crossfactor loadings or low correlations with their scale scores were either deleted or revised. In addition, four new items were written to better assess preparation sentiments. The revised SOLMI consisted of 24 items developed to reflect the following learning stages: precontemplation (6 items), contemplation (5 items), preparation (8 items), and action (5 items).

\section{Confirmatory Factor Analysis of Revised SOLMI}

Participants and procedure. Sample 2 consisted of 173 students enrolled in a large introductory Management Information Systems (MIS) course. Like the Principles of Management course in Sample 1, this introductory MIS course used a large auditorium-based lecture format to cover the foundation content areas of a management discipline. Following the timing employed with Sample 1, the revised SOLMI was administered during Week 3 of the academic quarter. No demographic information was available for Sample 2 participants.

Analyses. Confirmatory factor analyses (CFAs) were used to assess the structure of the revised SOLMI items. Three models were tested and compared to each other with regard to their goodness of fit. First, a null single-factor model was examined. Second, a three-factor model was tested where preparation items were forced to load with action items. The preparation construct is characterized by recognizing the benefits of change (i.e., contemplation), as well as exhibiting 
small behavioral changes (i.e., action), but the individual has not yet reached full action sentiments (Prochaska et al., 1992). Because the new preparation items added to the SOLMI reflected small behavioral changes, the three-factor model forced the items to load on the action factor. Finally, the four-factor model matching the design of the SOLMI was tested.

As advocated by Medsker, Williams, and Holahan (1994), multiple goodnessof-fit measures are reported because of the debate over confirmatory fit indexes (e.g., Mulaik et al., 1989). Although the chi-square-to-degree-of-freedom ratio statistic must be interpreted cautiously because of its sensitivity to sample size, Carmines and McIver (1981) noted that exceeding a threshold of 2 indicates an unacceptable model fit. The root mean square estimate of approximation (RMSEA) is a population-based index (averaged standardized residual per degree of freedom) relatively insensitive to sample size. RMSEAs of less than .05 indicate a close fit, values of less than .08 suggest a relatively good fit of the model, while values less than .10 are considered fair (Browne \& Cudeck, 1993). Browne and Cudeck's Expected Cross-Validation Index (ECVI) standard is geared toward identifying a model that fits well, is simple, and stands a better chance of fitting in a new sample than models that are not simple. Although there are no apparent statistical guidelines for the ECVI, smaller values indicate that a model is expected to cross-validate on a new sample (Loehlin, 1998). Finally, common practice suggests that the Comparative Fit Index (CFI) should exceed .90 in order for a model to not be rejected.

CFA results. In reviewing the results of the CFA, modification index values (Long, 1983) indicated that the models could be improved by dropping three items. Further examination of the items showed that all involved an aspect of performance (i.e., "I would rather live with my Management Information System performance than try to improve upon it"). Because these three items exhibited wording that was inconsistent with the 21 remaining items, they were deleted from all CFA analyses. As a result, we used CFAs to examine the fit of three models using only the remaining 21 items.

Consistent with our expectations, the CFAs indicated that our four-factor model fit the data better than the competing three-factor and null models. In assessing model fit, we computed a ratio of the final four-factor model's chi square to degrees of freedom $(336.03 / 187=1.80)$ that was below the 2 threshold suggested by Carmines and McIver (1981) and better than the three-factor $(521.10 / 186=2.80)$ and the null model $(2288.76 / 210=10.90)$. Furthermore, the four-factor model's fit indexes indicated that the model fit the data better than either competing model, as evidenced by the smaller RMSEA (.07 versus .10 and .24 for the three- and one-factor models, respectively), smaller ECVI values (2.50 versus 3.62 and 13.79 for the three- and one-factor models, respectively), and a CFI of .93 (compared to .84 for the three-factor solution and .00 for the null model). In sum, the results indicated that although the three-factor model 
exhibited a better fit than the null model $(p<.01)$, the four-factor model displayed a superior fit $(p<.01)$ over the three-factor and null models.

Table 1 reports the final set of 21 items and their structure coefficients, all of which were greater than $.54(p<.001)$. Coefficient alphas for the resulting SOLMI scales in Sample 2 were as follows: precontemplation $(\alpha=.77)$, contemplation $(\alpha=.77)$, preparation $(\alpha=.92)$, and action $(\alpha=.88)$. As the stage theory imposes, the factors were allowed to correlate in the CFA. Observed correlations ranged from -.76 to $.69(p<.01)$.

\section{Primary Study}

\section{Overview of Data Collection}

A third and primary sample (Sample 3) was used to test our hypotheses regarding the reliability and validity of the final SOLMI instrument. Data collection in Sample 3 occurred the following semester after data collection in Sample 1, and consisted of 476 undergraduates enrolled in an introductory Principles of Management course. Following the approach used in Sample 1, these 476 participants completed the SOLMI in their discussion/lab section at Week 3 of a 10-week academic term. This initial administration was labeled Time 1. Participants also completed the SOLMI a second time (Time 2$)$ at 1-week $(n=$ 73), 3-week ( $n=70)$, or 7-week $(n=165)$ intervals.

In addition to the two SOLMI administrations, 348 students in the sample also agreed to complete a second questionnaire consisting of all other self-report measures (e.g., control variables, dispositional criteria). This questionnaire was administered 7 weeks after the initial administration of the SOLMI. Furthermore, non-self-report performance criteria, including course performance measures (e.g., exam grades) and lab instructor assessments of student help-seeking behavior, were available for all participants. However, data were deleted from 100 participants because one of the lab instructors assisting with data collection deviated from standardized data-collection procedures. In addition, 14 students ultimately dropped the course. Therefore, the usable sample size was reduced to 362 (76\%). Of these participants, 214 (59\%) male, 329 (91\%) White, and roughly $351(97 \%)$ junior standing. Average age of the sample was 21.3 years $(S D=1.5)$.

Only participants with complete matching data records (2 SOLMI administrations, dispositional questionnaire, and non-self-report performance measures) were included in the analyses. This resulted in a complete data set of 207 participants. Of these 207 participants, $61(70 \%)$ had Time 2 SOLMI collections at the 1-week interval, 53 (76\%) at 3 weeks, and 93 (56\%) at 7 weeks. Results of a oneway MANOVA indicate that there were no significant differences between the deleted and retained participant groups for all control and criterion variables. All remaining analyses were computed using the 207 participants. 


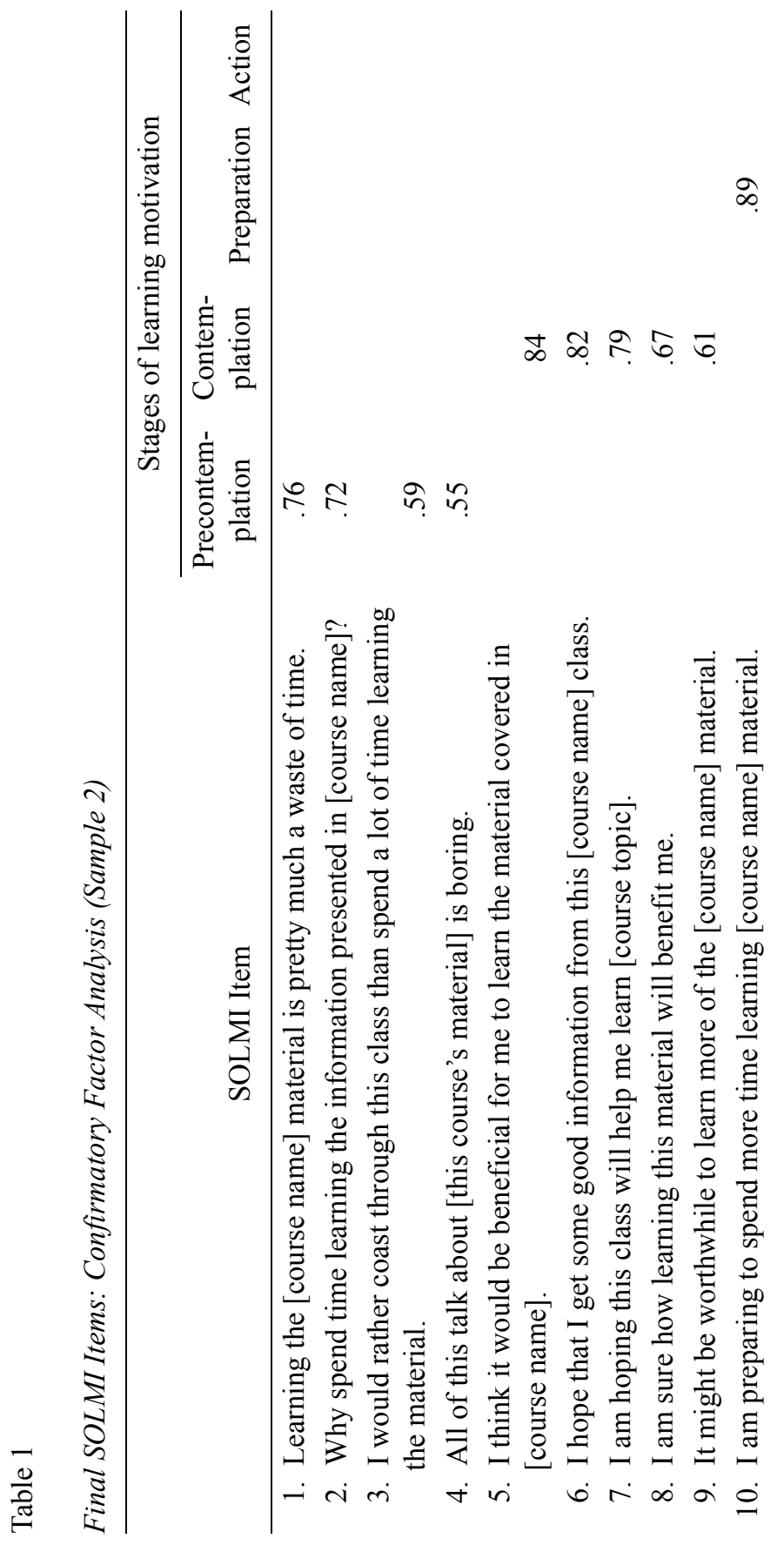


STAGES OF LEARNING MOTIVATION 1433

œ

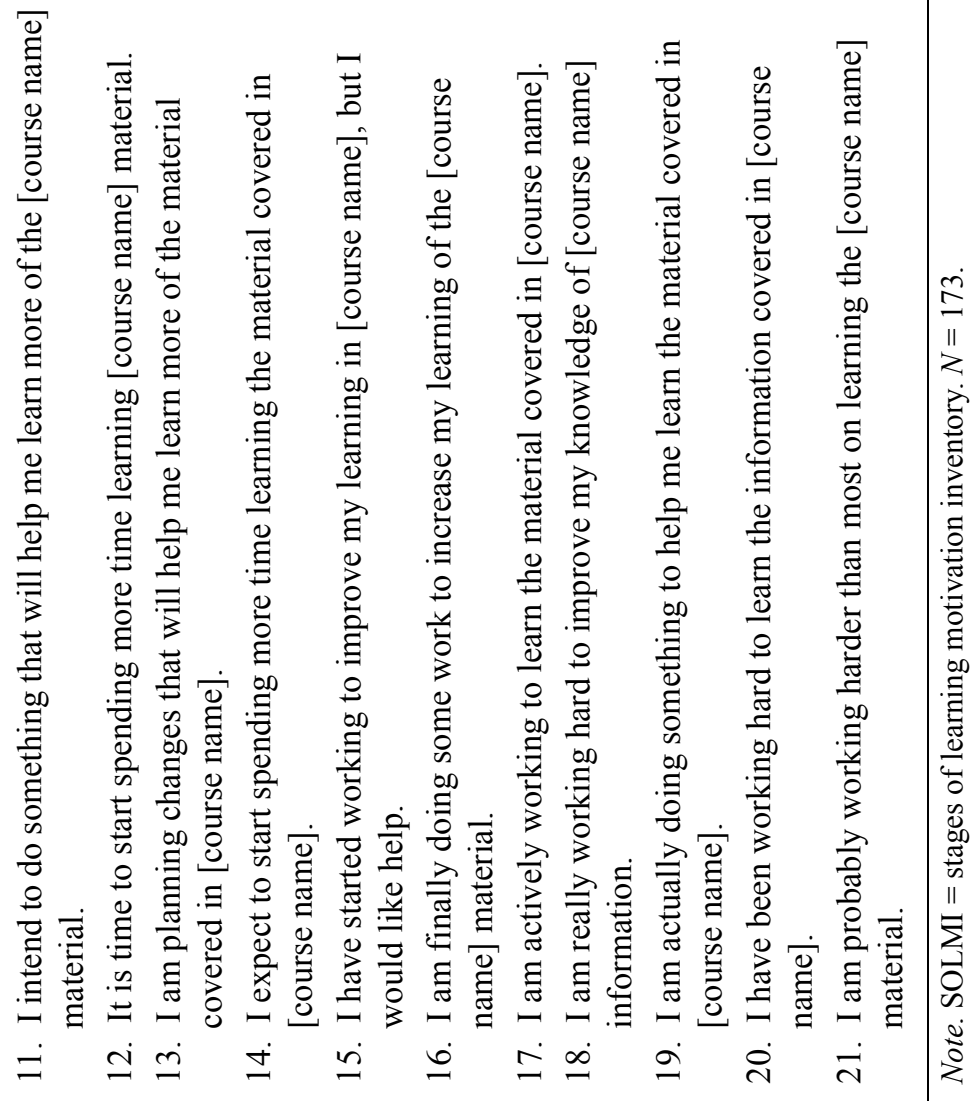




\section{Measures}

Predictors. The final 21-item version of the SOLMI, which includes scales for each of the four stages of learning motivation, was the primary predictor. Responses were made on a 6-point Likert scale ranging from 1 (strongly disagree) to 6 (strongly agree). Coefficient alphas for the four stage scales at Time 1 were as follows: precontemplation, $\alpha=.81$; contemplation, $\alpha=.89$; preparation, $\alpha=.85$; and action, $\alpha=.78$.

To explore the ability of the SOLMI to predict variance not accounted for by traditional measures of learning motivation, a version (four adapted items) of Noe and Schmitt's (1986) motivation to learn measure was used $(\alpha=.77)$. A sample item is "I am learning as much as I can of this material." Items were scored on a 6-point scale ranging from 1 (strongly disagree) to 6 (strongly agree).

Because general cognitive ability is an important determinant of training success (Ackerman, 1992; Hunter \& Hunter, 1984; Reilly \& Warech, 1994), it is important for any study attempting to determine if individual characteristics explain incremental variance in learning to include general cognitive ability (Colquitt et al., 2000). Students' grade point average (GPA) is often used as a proxy for general cognitive ability (e.g., Caldwell \& Burger, 1998). Cable and Judge (1997) found that students reported nearly identical GPAs as found in their files in the career office ( $M$ difference $=0.01, r=.95, p<.01)$. Consequently, GPA information was self-reported by participating students and ranged from 2.1 to 4.0 , with $35 \%$ of the students reporting a "B" average (3.0) or better.

Criteria measures. We hypothesized that students' learning motivation would relate to class performance, behavior, and attitude criteria. We assessed students' learning of the course material through their performance on eight exams administered during the academic term. A typical exam consisted of 30 to 35 multiplechoice questions germane to the material covered in 4 days of lecture. Exam averages ranged from $61.1 \%$ to $94.4 \%(M=82.21, S D=6.29)$.

At the conclusion of the class, each graduate teaching assistant (GTA) was given a list of their lab students who were participating in the research. The GTAs gave a help-seeking rating of how often each student sought their help in person (e.g., during office hours, after a lab) in learning the class material. The rating was made on a 5-point Likert scale ranging from 0 (never) to 5 (five or more times; $M=1.15, S D=2.22$ ).

We assessed class attendance with a single self-report item: "How often did you attend Principles of Management lectures?" $(1=$ never to $5=$ always; $M=$ $4.10, S D=1.13$ ). We acknowledge that use of an objective measure of attendance would eliminate common method variance concerns. However, the size (two sections each, with close to 400 students) and policy (attendance was not required or taken) made this impractical. 
Three items were modified from the job satisfaction scale of Cammann, Fichman, Jenkins, and Klesh's (1983) Michigan Organizational Assessment Questionnaire (MOAQ) to assess class satisfaction. A sample item is "All in all, I am satisfied with this class." Responses were made on a 6-point scale ranging from 1 (strongly disagree) to 6 (strongly agree). Coefficient alpha for the scale was .87 .

Demographic control variables. Because of concerns that the nonrandom assignment of students to class sections, lab instructor, and lab time might contaminate the learning motivation and performance measures, each was included as a control variable in all analyses. In addition, demographics including student classification (e.g., junior, senior), age, race, and gender were controlled in all analyses.

Attitudinal control variables. Since two of the criteria (class attendance and satisfaction) were self-reported, inflation in the relationships as a result of samesource bias among variables cannot be ruled out. We took several steps to address this problem. In addition to incorporating a 7-week time lag between collection of the initial SOLMI data and the criterion measures, positive affectivity (PA) and negative affectivity (NA; Watson, Clark, \& Tellegen, 1988) scales were included to help control for any dispositionally based response tendencies (Spector \& Brannick, 1995). For each of 20 emotions, students indicated the extent to which they had felt (over the past 2 weeks) a certain way using a 5-point scale ranging from 1 (very slightly or not at all) to 5 (extremely). Alphas for each of the 10-item PA (e.g., interested, excited) and NA (e.g., distressed, upset) scales were .87 and .81 , respectively. Finally, seven items from the self-deception subscale $(\alpha=.71)$ of the Balanced Inventory of Desirable Responding (BIDR; Paulhus, 1991) were employed as a final control. A sample item is "I always know why I like things." Responses were made on a 6-point scale ranging from 1 (strongly disagree) to 6 (strongly agree).

\section{Results}

Descriptive statistics and intercorrelations among the variables collected in the primary sample (Sample 3) and used in the hypothesis tests are reported in Table 2. As one might expect, the traditional measure of learning motivation was related negatively with precontemplation and positively with the remaining three SOLMI scales scores and each of the criteria. No SOLMI scales were related to our surrogate of general cognitive ability, GPA. Students' precontemplation scores were related negatively with the four criteria, and preparation was related negatively to students' exam average. Finally, 9 of the remaining 11 correlations between the SOLMI scale scores and criteria exhibited positive relationships.

\section{Classifying Respondents Into Stages}

Hypotheses for the study were designed to examine the construct validity of the stage-based learning motivation inventory (SOLMI). Stage theory suggests 


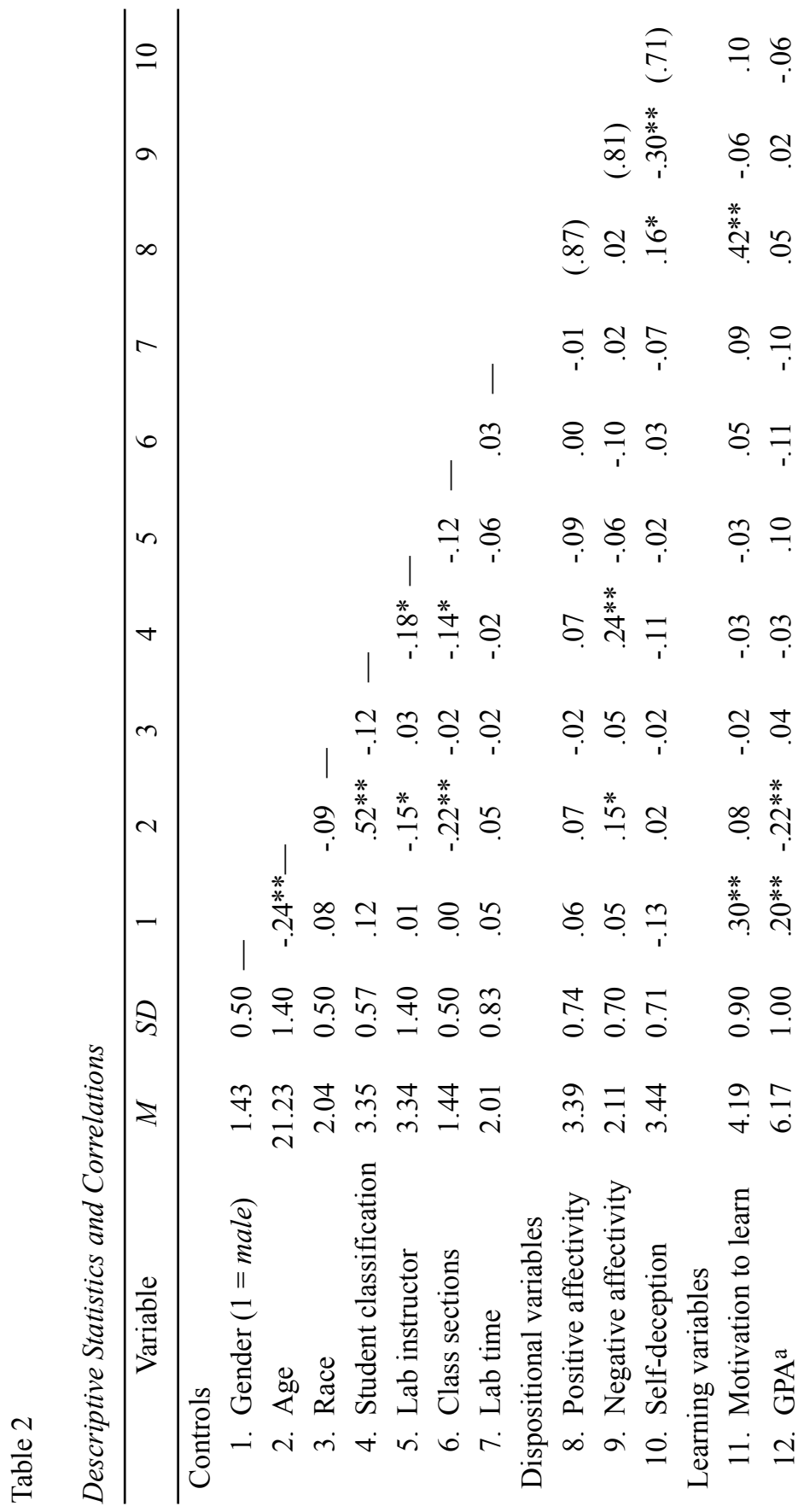




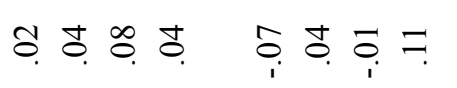

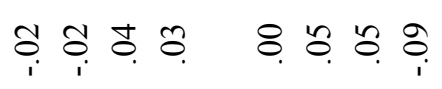

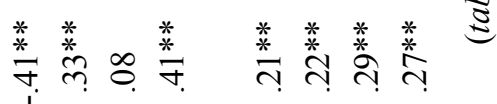

$\stackrel{\infty}{\circ}:$

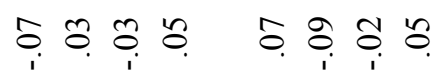

\& $\vec{i}_{i} \&$ \& 운

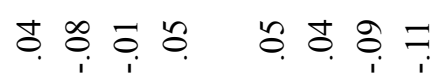

कृ:

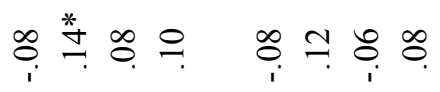

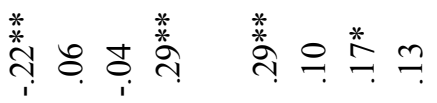

๙

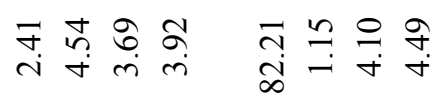

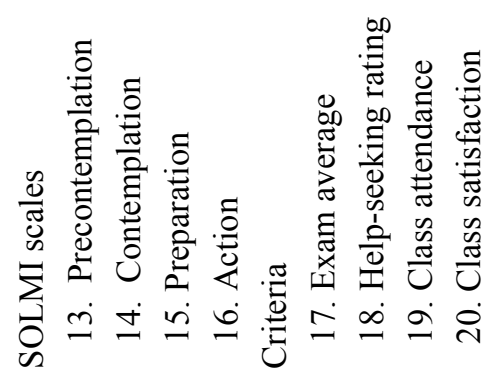


1438 COLE ET AL.

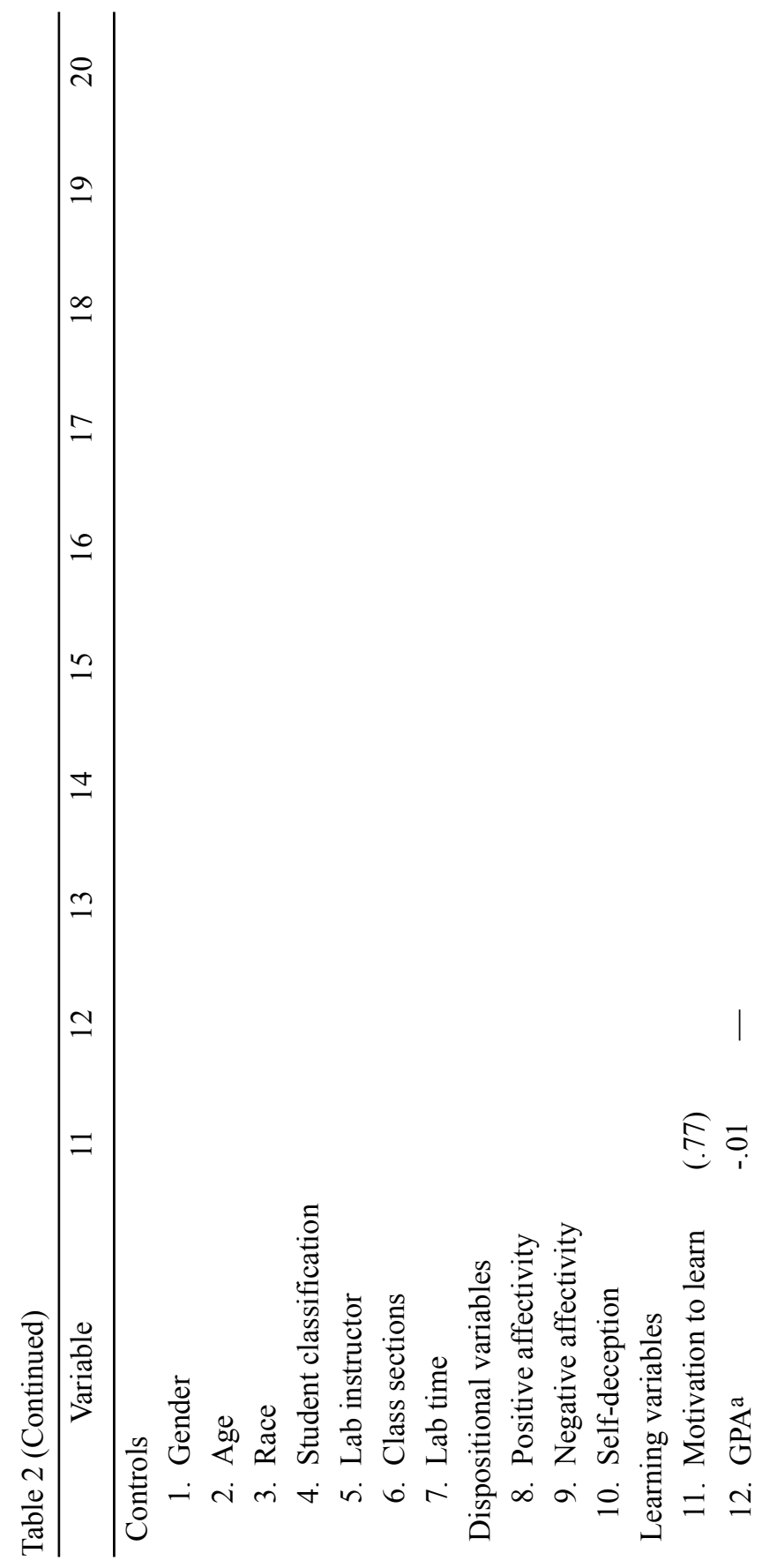




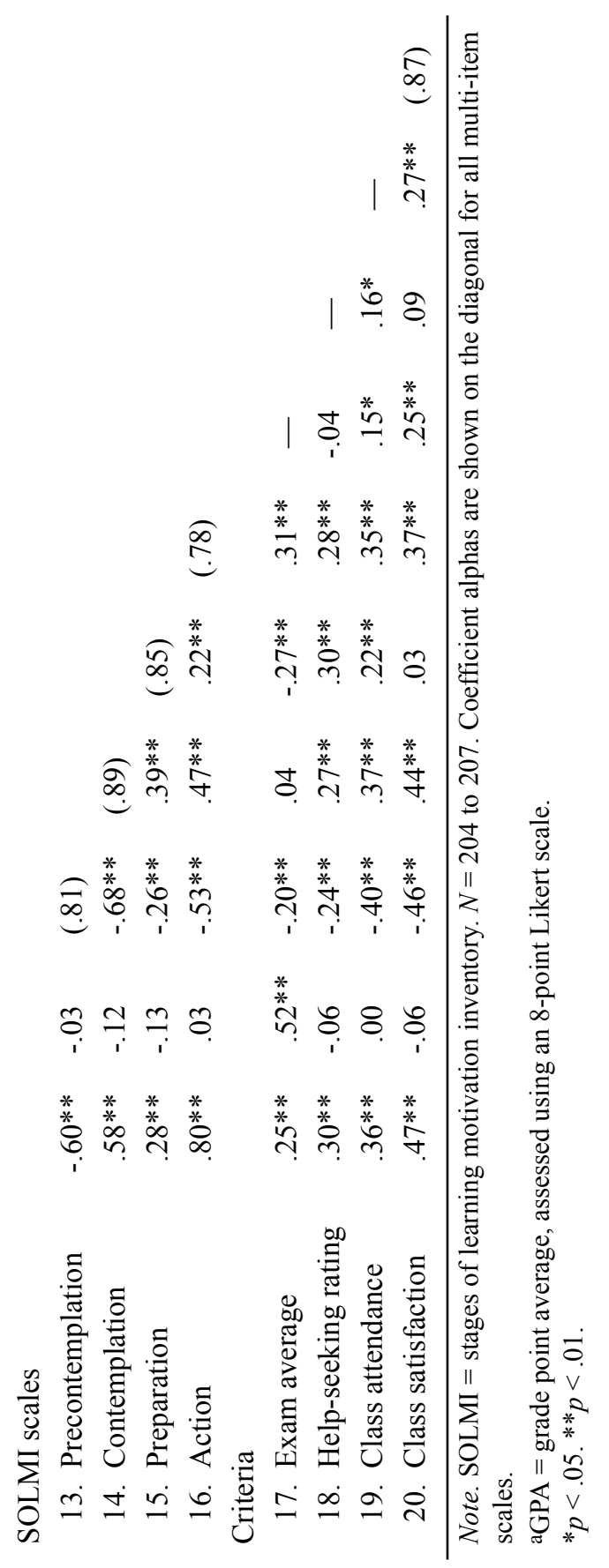


Table 3

Test-Retest Reliabilities and Alphas of the Stages of Learning Motivation (SOLMI) Scales at 1-Week, 3-Week, and 7-Week Retest Intervals

\begin{tabular}{|c|c|c|c|c|c|c|}
\hline \multirow{3}{*}{$\begin{array}{c}\text { Learning } \\
\text { motivation } \\
\text { stage }\end{array}$} & \multicolumn{6}{|c|}{ Time in weeks } \\
\hline & \multicolumn{2}{|c|}{1 week } & \multicolumn{2}{|c|}{3 weeks } & \multicolumn{2}{|c|}{7 weeks } \\
\hline & $\begin{array}{l}\text { Test- } \\
\text { retest }\end{array}$ & $\alpha$ & $\begin{array}{l}\text { Test- } \\
\text { retest }\end{array}$ & $\alpha$ & $\begin{array}{l}\text { Test- } \\
\text { retest }\end{array}$ & $\alpha$ \\
\hline Precontemplation & .80 & .81 & .69 & .73 & .54 & .76 \\
\hline Contemplation & .77 & .89 & .68 & .89 & .49 & .86 \\
\hline Preparation & .69 & .85 & .56 & .90 & .38 & .85 \\
\hline \multirow[t]{2}{*}{ Action } & .68 & .78 & .62 & .90 & .60 & .89 \\
\hline & \multicolumn{2}{|c|}{$N=61$} & \multicolumn{2}{|c|}{$N=53$} & \multicolumn{2}{|c|}{$N=93$} \\
\hline
\end{tabular}

that people primarily occupy one stage at a time or are in the process of moving from one stage to another (Prochaska et al., 1992). Therefore, prior to testing Hypotheses 1 and 2, it was necessary to classify respondents according to the primary stage that they occupied at each SOLMI administration. Following previously validated staging classification algorithms for use with the stages-ofchange model (DiClemente et al., 1991; Levesque et al., 1999, 2001), respondents were classified into stages. Specifically, students were classified into the stage for which they scored highest. If students' highest scale score was for precontemplation, they were coded as being in the precontemplation stage. If students' highest scale score was for contemplation, they were coded as occupying the contemplation stage, and so on, until all students were coded into one of the four stages. In only 32 out of 414 classifications $(207$ students $\times 2$ SOLMI administrations), were a student's scale scores equally high for more than one stage. Following Prochaska et al., we interpreted these ties as demonstrating movement from one stage to another, and coded the student as being in the more advanced learning motivation stage.

The stage theory of learning motivation argues that persons progress (or regress) through stages over time. For most people, the change process is spiral, not linear (Prochaska \& DiClemente, 1983a; Prochaska et al., 1992). Thus, some individuals often relapse to earlier stages before they achieve lasting behavioral change. To examine students' movement among the learning motivation stages, we performed two sets of analyses.

First, we examined persons' test-retest reliabilities between their Time 1 scale scores and their scale scores at Time 2 (either 1-, 3-, or 7-week intervals 
after Time 1). Consistent with the stage theory, the four scales for each time interval exhibited increasingly smaller test-retest reliabilities as the interval between Time 1 and Time 2 was increased. As reported in Table 3, the test-retest reliabilities for precontemplation decreased from .80 at the 1-week interval, to .69 at 3 weeks, and .54 at 7 weeks. The progression for contemplation was .77 to .68 to .49. For preparation it was .69 to .56 to .38 . Finally, the test-retest reliabilities for the 1-week, 3-week, and 7-week intervals for action progressed from .68 to .62 to .60 , respectively.

To confirm that these results were not a result of internal inconsistencies of the scales, coefficient alphas were computed for the scales at Time 1 and each of the three Time 2 intervals. The alphas at the Time 2 intervals were consistent with those at Time 1 . This, coupled with the progressively decreasing test-retest reliabilities, suggests that there was scale movement over time.

To investigate the nature of stage movement in the primary sample, students' occupied stage at Time 1 was compared to their stage at their Time 2 retest administration. Persons were coded as regressing $(-1=$ moving backward to an earlier stage $)$, no change $(0=$ residing in the same stage $)$, or progressing $(1=$ moving forward to a latter stage) at each of the three test-retest administrations. At the 1 -week interval, $69 \%$ remained in the same stage that they occupied a week earlier, $16 \%$ regressed, and $15 \%$ progressed. At the 3 -week interval, $62 \%$ remained in the same stage, $17 \%$ regressed, and $21 \%$ progressed. Finally, for those respondents who completed the Time 2 SOLMI at the 7-week interval, $63 \%$ exhibited no change, $20 \%$ regressed, and $16 \%$ progressed. Consistent with the stage model, the pattern of results suggest the SOLMI can be used to establish the learning stage occupied by an individual and track movement between stages.

\section{Hypothesis Testing}

Because each of the four SOLMI scales assesses a different stage, it was expected that respondents would exhibit a peaked profile; that is, a high score on one scale and significantly lower scores on the others (Hypothesis 1 ). As a result of small numbers of students in some of the stages $(<10)$, we used a nonparametric Kruskal-Wallis one-way ANOVA on rank orders to test Hypothesis 1. In all four SOLMI administrations (Time 1 and the 1-week, 3-week, and 7-week Time 2 intervals), the results generally confirmed the peaked profile hypothesis. The results for the Time 1 scores were consistent with Hypothesis 1. At Time 1, persons coded as precontemplators exhibited higher $(H=21.72, p<.001)$ precontemplation scale scores $(M=4.32)$ than the scores for contemplation $(M=$ $2.77)$, preparation $(M=3.22)$, and action $(M=2.78)$. Persons classified as contemplators had higher contemplation scores $(M=4.78 ; H=44.94, p<.001)$ than the scores for precontemplation $(M=2.29)$, preparation $(M=3.68)$, and action 
$(M=3.84)$. A similar pattern was found for those in the preparation stage $(H=31.10, p<.001)$ and those in the action stage $(H=50.36, p<.001)$. In all, this pattern of results supporting Hypothesis 1 held for 13 of the 16 profiles (4 stages $\times 4$ SOLMI administrations).

The three nonsupporting profiles from the Time 2 intervals were as follows. Although respondents for the 1-week interval SOLMI administration exhibited a peaked profile for contemplation and action, those in the precontemplation or preparation stages did not have respective scale means significantly higher than the other scale means. At the 7-week interval administration, students categorized in the preparation stage did not score significantly higher on preparation than they did on the other stage scales.

Hypothesis 2 predicted that persons classified in the action stage at the initial SOLMI assessment would perform better and have more proactive behaviors and positive class attitudes than students classified in the other three stages. Because Lilliefors and Shapiro-Wilks's (for sample sizes under 50) test for normality indicated help-seeking rating, class attendance, and class satisfaction were not normally distributed, one-way Kruskal-Wallis ANOVAs for rank orders were performed.

As predicted, students in the action stage at Time 1 performed better on class exams $(H=22.27, p<.001)$. Action stage students at the initial SOLMI administration performed better across course exams $(M=86.23)$ than did those in the precontemplation $(M=77.06)$, contemplation $(M=81.66)$, and preparation $(M=$ $80.55)$ stages. Also consistent with Hypothesis 2 , students initially classified in the action stage were more satisfied with the course at the end of the term than were those occupying other learning motivation stages $(H=13.73, p<.01)$. Students initially classified in the action stage reported being more satisfied with the class $(M=4.67)$ than did students in precontemplation $(M=2.86)$. Students in the contemplation and preparation stages were also more satisfied with the class than were precontemplation students ( $M \mathrm{~s}=4.60$ and 4.10 , respectively), but no less satisfied than those in the action stage. Results for class attendance were moderately significant $(H=6.43, p<.10)$. The results for help-seeking behaviors as reported by GTAs were not significant.

Hypothesis 3 predicted that students' occupied stages at the beginning and end of the academic term would interact and explain students' classroom performance (reflected in exam average). Theoretically, the action stage is the sole learning motivation stage where students are vigorously attempting to increase their knowledge and learning of the class material. The three earlier stages involve either being unaware of or resisting the idea of motivated learning (precontemplation), thinking about the benefits of increased learning efforts (contemplation), or at best preparing to spend additional time in learning the material (preparation). Moreover, the stage theory implies that the action stage is the optimal stage of motivated learning. Therefore, students who were in the 


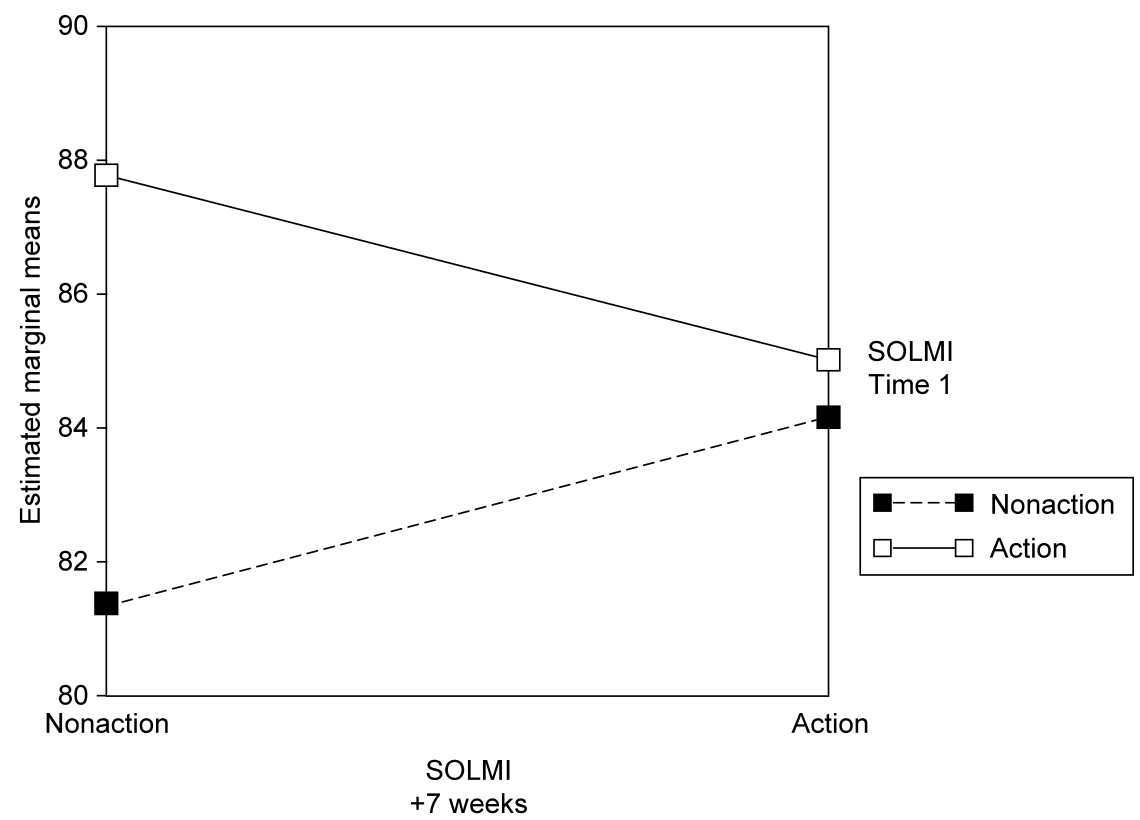

Figure 1. Exam average as a function of nonaction and action students at Time 1 and at 7 weeks.

action stage at both Time 1 and 2 were expected to perform the best, those progressing into the action stage expected to perform next best, and students regressing in stage or remaining static in a stage below action were expected to do relatively worse.

To test this hypothesis, we examined the Time 1 and Time 2 SOLMI responses for those 93 students who completed the Time 2 SOLMI at the maximal 7-week interval. For the reasons stated earlier, students occupying the precontemplation, contemplation, and preparation stages at Time 1 were coded into a single, nonaction group. Students occupying the action stage were classified into an action group. These same coding rules were applied to the 7-week interval SOLMI data. This classification scheme resulted in 74 nonaction and 19 action persons at Time 1, and 72 nonaction and 21 action persons at 7 weeks. Of these 93 persons, about one quarter shifted into or out of Stage 4 during this 7week period.

Levene's test indicated constant error variance, and Lilliefors and ShapiroWilks's tests indicated normality. Because exam average met ANOVA assumptions, a $2 \times 2$ (Time 1 Stage $\times 7$-Weeks Stage) ANOVA was used to test for predicted interaction effects for students' exam average. As hypothesized, an interaction effect was observed, $F(1,92)=4.26, p<.05$. As predicted, students 
who remained in a nonaction stage at both Time 1 and at 7 weeks had lower exam averages $(M=81.36)$ than did all other students who had occupied the action stage during at least one SOLMI administration ( $M \mathrm{~s}$ ranged from 84.16 to 87.79). However, as shown in Figure 1, the results concerning students who regressed out of the action stage were not as expected. Specifically, students who were in the action stage at Time 1 but had regressed to a nonaction stage by 7 weeks exhibited higher exam averages $(M=87.79)$ than did students classified as being in the action stage at Time 1 and at 7 weeks $(M=85.02)$.

Although the results for Hypotheses 1, 2, and 3 generally support our contention that the SOLMI adheres to the assumptions of a stage theory, they do not test the overall predictive validity of the SOLMI. Therefore, Hypothesis 4 predicted that the SOLMI would explain incremental variance in the important learning-related criteria beyond that accounted for by the controls and other predictors (i.e., motivation to learn and GPA). The correlations shown in Table 2 demonstrate that all four SOLMI scales were correlated with motivation to learn but were uncorrelated with GPA. In Tables 4 and 5, we present the results of hierarchical regressions of the SOLMI (collected at Time 1) with and without the traditional measures of motivation to learn and general cognitive ability used to predict the learning criteria. This aids in exploring the predictive adequacy of the SOLMI when used alone, and the incremental contribution over existing measures.

As shown in Table 4, when entered at Step 2, the Time 1 SOLMI scales accounted for significant incremental explained variance (ranging from $\Delta R^{2}=$ $.15, p<.001$, to $\Delta R^{2}=.22, p<.001$ ) across all four learning criteria (exam average, help seeking, class attendance, and class satisfaction) beyond that accounted for by the seven demographic controls. The SOLMI standardized betas after controlling only for demographics reveal an interesting pattern. Specifically, the action scale was the only one that was significant (all positive) across all four criteria. Precontemplation had a negative relationship with class attendance and satisfaction. The standardized betas for contemplation only reached significance for help seeking. Finally, the standardized betas for preparation were somewhat surprising. Time 1 preparation was positively related to help seeking, but negatively related to exam average and class satisfaction.

As shown in Table 5, when entered at Step 4, the Time 1 SOLMI scales accounted for incremental explained variance (ranging from $\Delta R^{2}=.05, p<.05$, to $\Delta R^{2}=.08, p<.001$ ) for each of the four learning-related criteria beyond that accounted for by the seven demographic controls (Step 1), three attitudinal controls (Step 2), and two learning variables of motivation to learn and GPA (Step 3). This pattern of results is consistent with our argument that the stage approach to assessing motivation to learn represented by the SOLMI adds insight into class behaviors and performance beyond the traditional measures of motivation to learn. 


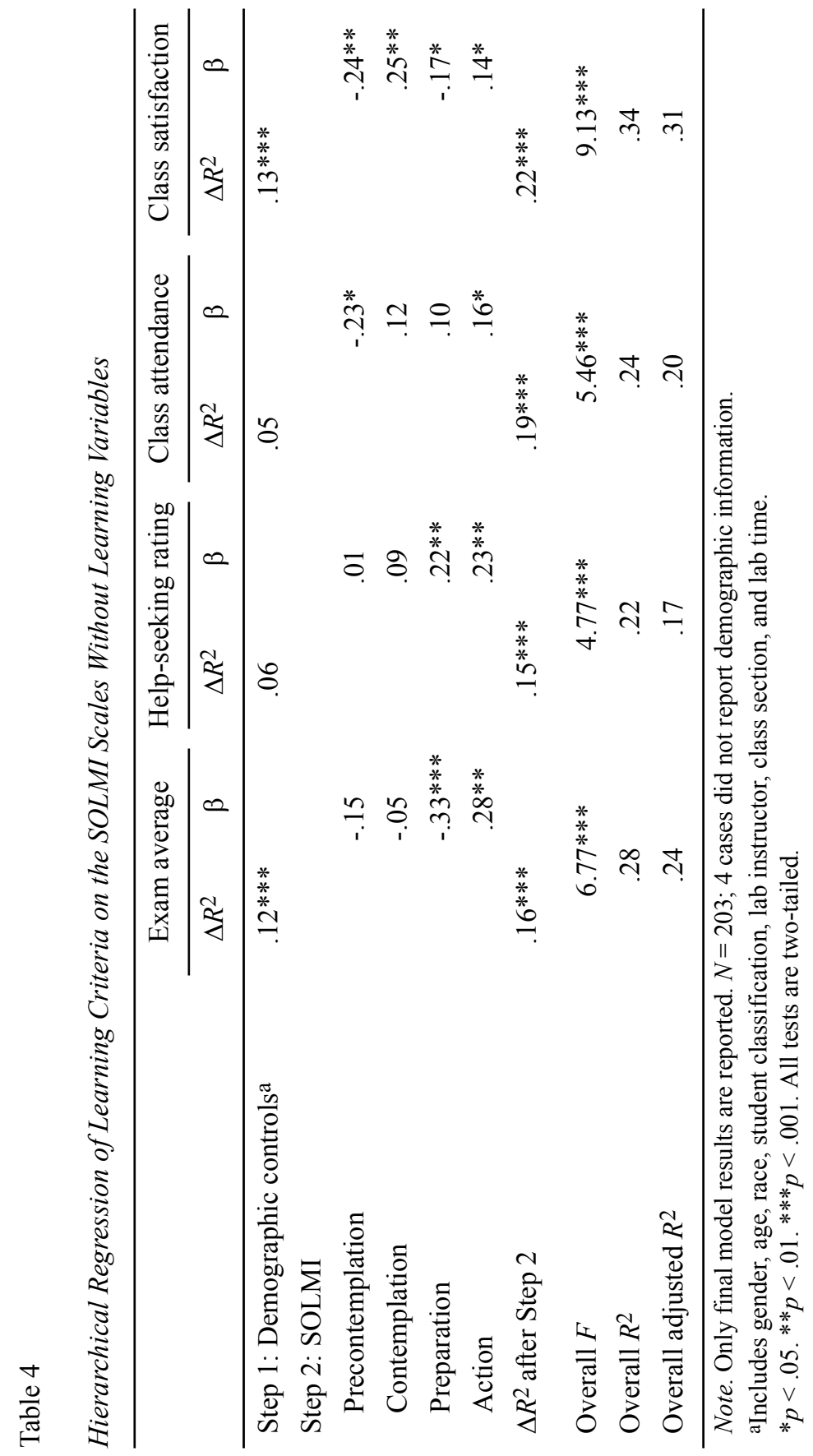




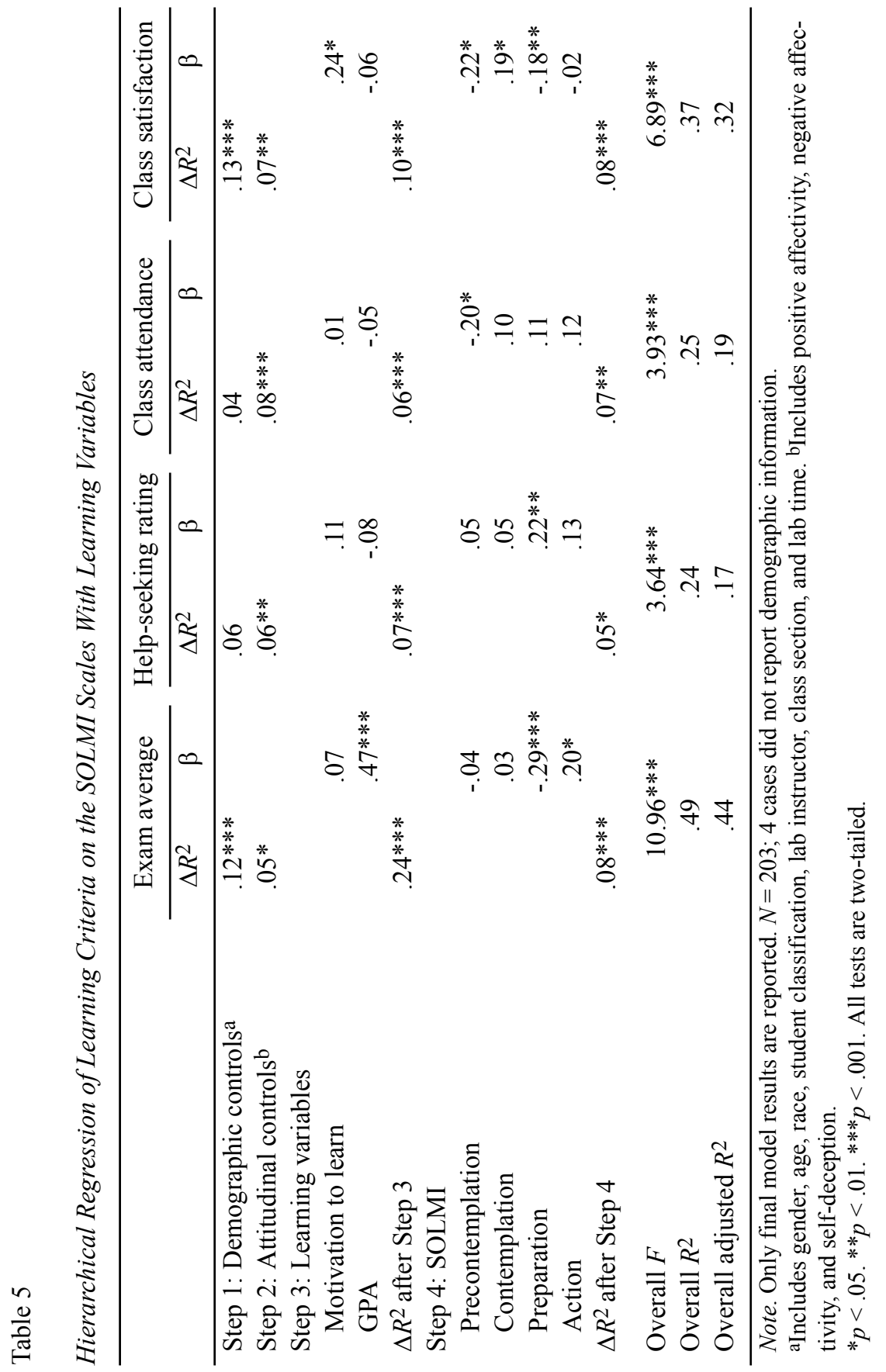


The pattern of standardized betas for the SOLMI for the two sets of equations (controlling and not controlling for the learning variables) was consistent with our predictions. Specifically, whereas it was significant for all four criteria when not controlling for motivation to learn and GPA, action was significant for only one when controlling for these learning variables. In contrast, the pattern of significance was the same for the other three stages across the two sets of equations. These results suggest that the action stage is most associated with more traditional treatments of motivation to learn and suggests that perhaps the SOLMI major contribution is the addition of an assessment of the stages of motivation prior to action.

\section{Discussion}

In this study, we responded to recent calls for more research on the focal construct of motivation to learn (e.g., Colquitt \& Simmering, 1998). Specifically, we applied a theoretical framework to develop a stage-based measure of learning motivation (the SOLMI) and provided preliminary tests of its ability to advance our understanding of the dynamics of motivation to learn. The primary purpose of our research was to develop a theory-based, construct-valid measure of individuals' stage-based learning motivations. Although typically conceptualized as a static, unidimensional construct, the results support our contention that there are advantages to operationalize learning motivation as a multidimensional, stage-based concept. Moreover, the results provide supporting evidence of the reliability and construct validity of the SOLMI as an assessment of the stages of learning motivation within a learning context and, as such, can serve as the basis for future research, instrument refinement, and application.

Our results suggest that the SOLMI was reliable in both internal consistency and ability to track change. In terms of internal reliability, the coefficient alphas for the SOLMI scales were stable across samples and administrations. Our stagebased approach also predicts movement between stages over time (e.g., Prochaska, 1979). Consistent with this expectation, SOLMI scale test-retest coefficients tended to decrease over time. In addition, we found that $35 \%$ of Sample 3 respondents either advanced or regressed to a different stage between the initial SOLMI assessment and their respective retest.

\section{Construct Validity of the SOLMI}

Consistent with Hypothesis 1 and stage theory, students' SOLMI scale scores exhibited a peaked profile (scores on one scale higher than scores on others). And for 13 of the 16 possible scale score comparisons (4 scales $\times 4$ administrations), the differences between the peak scale scores and the scores on the other three scales were significant. Of the three instances where the differences among the stage scores were not significant, one involved precontemplation 
at the 1-week administration, and two involved preparation from the 1 -week and 7-week administrations. In the first instance involving precontemplation, the sample size $(n=1)$ prohibited any type of inferences (even nonparametric) to be drawn.

The results for the preparation scale may be the result of the more transitionary nature of preparation sentiments. While preparation is treated as a distinct stage in Prochaska's theory (Prochaska et al., 1992), there are no items to assess preparation sentiments in Prochaska's work. Instead, Prochaska argued that persons residing in the preparation stage are characterized by high scores on contemplation and action. Thus, there is reason to expect persons occupying the preparation stage to hold either high contemplation sentiments (if the person is just moving into preparation) or high action sentiments (if the person is beginning to move into action). From this perspective, the absence of a peaked profile for preparation is easily understood. Future modifications of the SOLMI's preparation scale may help to differentiate more reliably individuals' preparation sentiments from those of contemplation or action.

Hypothesis 2 proposed that students occupying the action stage would outperform students residing in less motivated stages. The results indicate that students initially occupying precontemplation did not attend class as often and reported being less satisfied with the class than did all students in all other stages. These findings have important implications for all involved in the development of education and training programs. In the current study, students occupying the action stage (particularly early in the term) excelled in knowledge acquisition and also reported higher attendance and satisfaction levels.

What are the implications for an organizational training program where the majority of the employees involved reside in precontemplation or contemplation? The current results suggest such stage profiles would lead to higher than normal absenteeism and many trainees failing to learn essential, job-related skills. Thus, it is essential for trainers to conduct pre-training needs assessments and to match interventions to trainees' stages to expedite movement to the action stage.

In regard to Hypothesis 3, the interaction between students' initial SOLMI stage and their occupied stage, assessed 7 weeks later, was significant for exam average. As the stage theory of learning motivation predicts, persons crystallized within a nonaction stage of learning motivation had the lowest exam averages. Students progressing from nonaction to action received exam averages similar to students who reported being in action at both SOLMI administrations. Interestingly, students moving backward from action to the nonaction classification received the highest exam averages.

Why would students regressing from the action stage do better on exams? We think that it may involve a realization by some students that they can be successful without putting forth the level of effort implied in the action stage. A student in the action stage early in the term is likely to put more effort into learning and 
studying. If that student meets with moderate success, he or she is likely to continue to pursue that level of motivation (i.e., maintain the action stage). But what about students who find the material very easy and have great success early in the class? Will they maintain the same level of motivation? We think not. Therefore, we believe that it is possible that students who regressed from the action stage may have done so because the students realized they did not need to actively put in effort. Once this group recognized that they could turn their cognitive energies to things more intrinsically interesting or more demanding (e.g., another class or project), many would be expected to regress to a nonaction stage while maintaining a high exam average.

Our data provided us with a way to examine the possibility of this explanation. One would expect, for example, that students performing well with little effort would have higher mental abilities than others. Using GPA as a surrogate of mental ability, we examined whether or not the GPAs of those regressing out of the action stage were higher than the GPAs of those students remaining in the action stage. At the 3-week stage, students who regressed reported significantly higher GPAs than did students progressing to a latter stage. At 1 and 7 weeks, regressing students' GPAs were higher but did not reach statistical significance.

It would be interesting to examine how regressing students would perform in class activities, such as team projects due at the end of the academic term. Does their regression to a nonaction stage hinder their participation and performance in the group project, or does the challenge of the upcoming project motivate them to stay in the action stage or motivate them to progress back into it? It is impossible for us to test these questions with the present data and therefore suggest them as areas for future research.

Finally, as predicted in Hypothesis 4, the SOLMI explained incremental variance in four learning criteria after controlling for demographic characteristics, affect and response distortion variables, and traditional measures of motivation to learn and general cognitive ability. The SOLMI explained an average of 7\% additional variance beyond that of these 12 control variables. The fact that Hypothesis 4 was supported despite the statistical significance of the control variables and inclusion of traditional measures of motivation to learn and cognitive ability (GPA) illustrates the advantages of treating learning motivation from a multidimensional, stage-based perspective as assessed by the SOLMI.

\section{SOLMI Stages}

The pattern of results (correlations and standardized betas) shown in Tables 2 and 4 provide useful insight into the four stages of learning motivation. All of them were related significantly to the traditional motivation to learn measure (the correlation was negative for precontemplation), but were not correlated with GPA. This suggests that the learning motivation stages are independent of 
cognitive ability. Beyond these similarities, the results are often different across the four stages.

Precontemplation was negatively related to generally accepted positive learning behaviors, attitudes, and outcomes. From a needs-assessment perspective, precontemplation sentiments are expected to play a critical role. For example, precontemplative persons are important to identify because they are unlikely to display initiative, and, therefore, it is doubtful these persons will sign up for learning opportunities within organizational settings. Moreover, the data presented support this line of reasoning. When included in a regression equation with the other stage scales, precontemplation emerges as an independent negative predictor of class attendance and satisfaction (even after controlling for demographics, attitudes, motivation to learn, and GPA).

Contemplation was correlated positively with all the criteria examined in our study. However, when considered with all the stages, the regression results indicate that other stage scores were better predictors than was contemplation. Contemplation emerged as a predictor only for students' class satisfaction, and not for the more behavior-oriented help seeking and attendance or the outcomeoriented exam average. Consistent with the stages-of-change model, these results suggest that contemplation captures an attitudinal or cognitive dimension more so than a behavioral or action dimension of learning motivation.

The results for the preparation stage are the most inconsistent with our expectations and the most difficult to explain. As noted earlier, preparation traditionally has been treated as a transition stage and operationalized as scoring high on contemplation and action. We expected that preparation would be associated positively with our learning criteria. Unexpectedly, however, preparation was correlated negatively with exam average and unrelated to class satisfaction. Interestingly, preparation stands out when included with all other predictors in terms of predicting help seeking.

\section{Implications for Practice}

What might account for these results? More research is required, but we speculate that when treated as a distinct stage rather than a transition point, preparation may be a kind of limbo where there are preliminary positive behaviors. In this sense, preparation might be viewed as a protracted, almost procrastinating move from contemplation to action where positive behaviors and attempts to actively learn are experimented with rather than energetically embraced. In contrast to this explanation, it may be that people are in the preparation stage because they are unclear as to how to move to action. This is consistent with our finding that preparation is a consistent and unique predictor of help seeking. Obviously, more research on the nature of the preparation stage is needed to help understand its role in learning motivation. 
The results for the action stage are clear and straightforward. The action learning stage is associated with positive learning activities, attitudes, and outcomes. It is also clear that the action stage has the greatest overlap with traditional learning motivation.

The SOLMI can be used as a brief, self-report diagnostic instrument for development purposes in a wide variety of contexts. Past research has indicated that the stages of change are systematically related with different motivations, concerns, and intervention requirements (DiClemente \& Prochaska, 1982; Prochaska et al., 1992). It has also been shown empirically that the stagesof-change model provides a framework for categorizing stages-of-change motivations, as well as the interventions appropriate to support positive progress at each stage (Prochaska et al., 1994). Thus, the transtheoretical model of stages of change is facilitative not coercive; it assimilates the when, how, and why of behavioral change (Prochaska, 2000).

In a university setting, an educator who knows a priori where the majority of students' learning sentiments lie could successively tailor their teaching plan to engage students and enhance their motivation to learn. For example, it is our experience that many undergraduates enrolled in statistics courses generally are anxious, do not want to be in the class, or do not see the instrumentality of the class (i.e., precontemplation orientation). Yet, some educators proceed in their lesson plans by having students learn theorems and derive complex equations (i.e., action interventions). Such incongruities between motivations and interventions fail to address students' need to perceive a desired benefit, and move past the precontemplative stage. In this scenario, one might hypothesize that both the educator and students would benefit by first making the students aware of the benefits of statistics (i.e., moving them from precontemplation to contemplation) and, finally, having students actively engaged in more complex statistical calculations (i.e., action).

\section{Study Limitations}

As with most research, the current study has its limitations. The major limitation of the present study is the small sample sizes in some of the stage classifications. When appropriate, the use of nonparametric tests for our hypothesis tests helped to overcome this limitation. As argued by Siegel (1956), nonparametric tests are particularly suited for dealing with small samples not assumed to be drawn from a normal population. Despite being more conservative, the nonparametric tests supported many of the hypothesized relationships. Nonetheless, future research should replicate our results with a much larger and more diverse group of participants.

Some may consider the use of undergraduate college students a second limitation. Compared to more traditional designs, our choice of a university setting 
allowed us the opportunity to study a learning environment that rewards those who pursue learning opportunities. Consequently, the current findings portray learners as active participants, progressing and regressing through varied stages of learning motivation, each with a different learning experience. Because of its constrained nature (e.g., training exercises that proceed from simple to complex), we are unsure if we would have found similar results in a traditional training environment. However, we look forward to future researchers testing the SOLMI in such organizational contexts. Finally, the length of the current measure may limit its practicality in organizational settings where survey length and data access are restricted so invariably. Because the current study was the initial attempt to use the SOLMI, we chose to report the results using the 21 items. Future researchers can use our CFA results to develop a factorially pure, shorter version.

\section{Future Research}

Regarding future research, applications of the SOLMI should examine its applicability to other important learning criteria (e.g., knowledge transfer to the job), as well as contexts where the consequences for not learning are more severe. Future studies should incorporate experimental designs using quantitative or qualitative data to discern what events or processes provide the impetus for learning sentiments to shift between the motivational stages. Furthermore, with the development of artificial neural networks (e.g., Skapura, 1996), researchers are provided a rigorous classification methodology that could be used to categorize students into learning motivation profiles, and differences among these profiles could be interpreted. In addition, the SOLMI and appropriate contextspecific modifications of it could prove to be a useful tool in individual- and organizational-level research. From an individual level of analysis, behaviors that concern change and learning activities, particularly training and development, appear fruitful.

Finally, the multidimensional, stage-based approach to learning motivation, of which the SOLMI is one example, needs to be further examined, refined, and embedded in learning theory and application. We believe the results of our study show that such a line of inquiry has merit and the potential to improve our understanding of training motivation and training success.

\section{References}

Ackerman, P. L. (1992). Predicting individual differences in complex skill acquisition: Dynamics of ability determinants. Journal of Applied Psychology, 77, 598-614.

Baldwin, T. T., Magjuka, R. J., \& Loher, B. T. (1991). The perils of participation: Effects of choice of training on trainee motivation and learning. Personnel Psychology, 44, 51-65. 
Browne, M. W., \& Cudeck, R. (1993). Alternative ways of assessing model fit. In K. A. Bollen \& J. S. Long (Eds.), Testing structural equation models (pp. 136-162). Newbury Park, CA: Sage.

Cable, D. M., \& Judge, T. A. (1997). Interviewers' perceptions of personorganization fit and organizational selection decisions. Journal of Applied Psychology, 82, 546-561.

Caldwell, D. F., \& Burger, J. M. (1998). Personality characteristics of job applicants and success in screening interviews. Personnel Psychology, 51, 119-125.

Cammann, C., Fichman, M., Jenkins, G. D., \& Klesh, J. R. (1983). Assessing the attitudes and perceptions of organizational members. In S. E. Seashore, E. E. Lawler, P. H. Mirvis, \& C. C. Cammann (Eds.), Assessing organizational change. (pp. 71-138). New York, NY: John Wiley and Sons.

Campbell, J. P. (1989). An agenda for theory and research. In I. L. Goldstein (Ed.), Training and development in organizations (pp. 469-486). San Francisco, CA: Jossey-Bass.

Carmines, E. G., \& McIver, J. P. (1981). Analyzing models with unobserved variables: Analysis of covariance structures. In G. W. Bornstedt \& E. F. Borgatta (Eds.), Social measurement, current issues (pp. 65-115). Beverly Hills, CA: Sage.

Colquitt, J. A., LePine, J. A., \& Noe, R. A. (2000). Toward an integrative theory of training motivation: A meta-analytic path analysis of 20 years of research. Journal of Applied Psychology, 85, 678-707.

Colquitt, J. A., \& Simmering, M. J. (1998). Conscientiousness, goal orientation, and motivation to learn during the learning process: A longitudinal study. Journal of Applied Psychology, 83, 654-665.

Coovert, M. D., \& McNelis, K. (1988). Determining the number of common factors in factor analysis: A review and program. Educational and Psychological Measurement, 48, 687-692.

DeVellis, R. S. (1991). Scale development: Theory and application. Newbury Park, CA: Sage.

DiClemente, C. C., \& Prochaska, J. O. (1982). Self-change and therapy change of smoking behavior: A comparison of processes of change in cessation and maintenance. Addictive Behavior, 7, 133-142.

DiClemente, C. C., Prochaska, J. O., Fairhurst, S. K., Velicer, W. F., Velasquez, M. M., \& Rossi, J. S. (1991). The process of smoking cessation: An analysis of precontemplation, contemplation, and preparation stages of change. Journal of Consulting and Clinical Psychology, 59, 295-304.

Goldstein, L. L. (1993). Training in organizations: Needs assessment, development, and evaluation (3rd ed.). Monterey, CA: Brooks/Cole.

Harris, S. G., \& Cole, M. S. (1999, August). A stages of change perspective on motivation to learn in a leadership development context: An empirical 
examination. Paper presented at the annual Academy of Management Meeting, Chicago, IL.

Hunter, J. E., \& Hunter, R. F. (1984). Validity and utility of alternative predictors of job performance. Psychological Bulletin, 96, 72-98.

Levesque, D. A., Prochaska, J. M., \& Prochaska, J. O. (1999). Stages of change and integrated service delivery. Consulting Psychology Journal: Practice and Research, 51, 226-241.

Levesque, D. A., Prochaska, J. M., Prochaska, J. O., Dewart, S. R., Hamby, L. S., \& Weeks, W. B. (2001). Organizational stages and processes of change for continuous quality improvement in health care. Consulting Psychology Journal: Practice and Research, 53, 139-153.

Loehlin, J. C. (1998). Latent variable models: An introduction to factor, path, and structural analysis (3rd ed.). Mahwah, NJ: Lawrence Erlbaum.

Long, J. S. (1983). Confirmatory factor analysis. Beverly Hills, CA: Sage.

Mathieu, J. E., \& Martineau, J. W. (1997). Individual and situational influences in training motivation. In J. K. Ford, S. W. J. Kozlowski, K. Kraiger, E. Salas, \& M. S. Teachout (Eds.), Improving training effectiveness in work organizations (pp. 193-222). Hillsdale, NJ: Lawrence Erlbaum.

Mathieu, J. E., Tannenbaum, S. I., \& Salas, E. (1992). Influences of individual and situational characteristics on measures of training effectiveness. Academy of Management Journal, 35, 828-847.

McConnaughy, E. A., DiClemente, C. C., Prochaska, J. O., \& Velicer, W. F. (1989). Stages of change in psychotherapy: A follow-up report. Psychotherapy, 26, 494-503.

Medsker, G. J., Williams, L. J., \& Holahan, P. J. (1994). A review of current practices for evaluating causal models in organizational behavior and human resources management research. Journal of Management, 20, 439-464.

Mulaik, S. A., James, L. R., Van Alstine, J., Bennett, N., Lind, S., \& Stilwell, C. D. (1989). Evaluation of goodness-of-fit indices for structural equation models. Psychological Bulletin, 105, 430-445.

Noe, R. A. (1986). Trainees' attributes and attitudes: Neglected influences on training effectiveness. Academy of Management Review, 11, 736-749.

Noe, R. A., \& Schmitt, N. (1986). The influence of trainee attitudes on training effectiveness: Test of a model. Personnel Psychology, 39, 497-523.

Noe, R. A., \& Wilk, S. L. (1993). Investigation of the factors that influence employees' participation in development activities. Journal of Applied Psychology, 78, 291-302.

Noe, R. A., Wilk, S. L., Mullen, E. J., \& Wanek, J. E. (1997). Employee development: Construct validation issues. In J. K. Ford (Eds.), Improving training effectiveness in work organizations (pp. 153-189). Mahwah, NJ: Lawrence Erlbaum.

Nunnally, J. C. (1978). Psychometric theory. New York, NY: McGraw-Hill. 
Paulhus, D. L. (1991). Measurement and control of response bias. In J. P. Robinson, P. R. Shaver, \& L. S. Wrightsman (Eds.), Measures of personality and social psychological attitudes (pp. 17-59). San Diego, CA: Academic Press.

Prochaska, J. O. (1979). Systems of psychotherapy: A transtheoretical analysis. Homewood, IL: Dorsey.

Prochaska, J. M. (2000). A transtheoretical model for assessing organizational change: A study of family service agencies' movement to time-limited therapy. Families in Society: The Journal of Contemporary Human Services, 81, 76-84.

Prochaska, J. O., \& DiClemente, C. C. (1982). Transtheoretical therapy: Toward a more integrative model of change. Psychotherapy: Theory, Research, and Practice, 19, 276-289.

Prochaska, J. O., \& DiClemente, C. C. (1983a). Stages and processes of selfchange of smoking: Toward an integrative model of change. Journal of Consulting and Clinical Psychology, 51, 390-395.

Prochaska, J. O., \& DiClemente, C. C. (1983b). Transtheoretical therapy: Toward a more integrative model of change. Psychotherapy: Theory, Research, and Practice, 20, 161-173.

Prochaska, J. O., DiClemente, C. C., \& Norcross, J. C. (1992). In search of how people change: Applications to addictive behaviors. American Psychologist, 47, 1102-1114.

Prochaska, J. O., DiClemente, C. C., Velicer, W. F., Ginpil, S., \& Norcross, J. (1985). Predicting change in smoking status for self-changers. Addictive Behavior, 10, 395-406.

Prochaska, J. O., DiClemente, C. C., Velicer, W. F., \& Rossi, J. S. (1993). Standardized, individualized, interactive, and personalized self-help programs for smoking cessation. Health Psychology, 12, 399-405.

Prochaska, J. O., Velicer, W. F., Rossi, J. S., Goldstein, M. G., Marcus, B. H., Rakowski, W., Fiore, C., Harlow, L. L., Redding, C. A., Rosenbloom, D., \& Rossi, S. R. (1994). Stages of change and decisional balance for 12 problem behaviors. Health Psychology, 13, 39-46.

Quinones, M. A. (1995). Pretraining context effects: Training assignment as feedback. Journal of Applied Psychology, 80, 226-238.

Reilly, R. R., \& Warech, M. A. (1993). The validity and fairness of alternatives to cognitive tests. In L. C. Wing \& B. R. Gifford (Eds.), Policy issues in employment testing (pp. 131-224). Norwell, MA: Kluwer Academic.

Siegel, S. (1956). Nonparametric statistics for the behavioral sciences. New York, NY: McGraw-Hill.

Skapura, D. M. (1996). Building heural networks. New York, NY: Addison-Wesley. Spector P. E., \& Brannick, M. T. (1995). The nature and effects of method variance in organizational research. International Review of Industrial and Organizational Psychology, 10, 249-274. 
Tannenbaum, S. I., \& Yukl, G. (1992). Training and development in work organizations. Annual Review of Psychology, 43, 399-441.

Thompson, B., \& Daniel, L. G. (1996). Factor analytic evidence for the construct validity of scores: A historical overview and some guidelines. Educational and Psychological Measurement, 56, 197-208.

Watson, D., Clark, L. A., \& Tellegen, A. (1988). Development and validation of brief measures of positive and negative affect: The PANAS scales. Journal of Applied Psychology, 54, 1063-1070.

Zwick, W. R., \& Velicer, W. F. (1986). Comparison of five rules for determining the number of components to retain. Psychological Bulletin, 99, 432-442. 